\title{
El presupuesto participativo en la Ciudad de México: modalidades y resultados
}

\section{Participatory budgeting at Mexico City: modalities and results}

\author{
doi: http://dx.doi.org/10.32870/
}

Alberto Escamilla Cadena

espiral.v26i74.7027

\section{Resumen}

El presente artículo aborda las modalidades y los resultados del presupuesto participativo como mecanismo de democracia directa utilizado en la Ciudad de México durante el periodo de 2011 a 2017. Se analizan la forma de organización de este instrumento y los rubros que se sometieron a consideración de los ciudadanos para que sus autoridades les asignaran una parte del presupuesto para su atención. También, se presentan la regulación jurídica que define la aplicación de estas consultas y las funciones que desempeñan en este proceso las instituciones de Gobierno local y electorales y las organizaciones vecinales. Por último, se consideran también los resultados que han arrojado estos ejercicios.

Palabras clave: democracia directa, presupuesto participativo, organizaciones vecinales, consultas, Ciudad de México.

\begin{abstract}
This article addresses the modalities and results of the participatory budget, a direct democracy mechanism that has been used in Mexico City from 201I to 2017. The paper analyzes the organization of this instrument, as well as the items that were submitted for the consideration of citizens so that their authorities could assign a part of the budget to it. In the same way, the legal regulation that defines the application of these consultations is presented, as well as the functions performed in this process by the local government and electoral institutions, and also the neighborhood organizations. Finally, the results of these exercises are also considered.
\end{abstract}

Keywords: Direct democracy, participatory budgeting, neighborhood organizations, consultations, Mexico City.

-Profesor-Investigador en la Universidad Autónoma Metropolitana (UAM), unidad Iztapalapa, México. ORCID: http://orcid.org/0000-0003-450I-938I aescamillac@hotmail.com Fecha de recepción: 07 de febrero de 2018. Fecha de aceptación: 10 de octubre de 2018. 


\section{Introducción}

El presente trabajo tiene como objetivo analizar las modalidades y los resultados de las consultas relativas al presupuesto participativo aplicadas en la Ciudad de México durante el periodo que va de 2011 a 2017. La intención es conocer la forma en que se organiza este ejercicio, así como los rubros que han seleccionado los habitantes de las demarcaciones territoriales de la ciudad para que sean atendidos por sus autoridades delegacionales. Con este instrumento de democracia directa, los colonos pueden sugerir que se asigne un porcentaje de dinero hacia ciertas áreas que consideran prioritarias. Si bien los recursos que designan los jefes delegacionales a las áreas seleccionadas por la población son apenas un porcentaje mínimo (5\%) del presupuesto anual que reciben, lo que no se traduce en una cantidad considerable, se debe tomar en cuenta que apenas se han desarrollado los primeros ejercicios que permiten a la ciudadanía seleccionar ciertos problemas metropolitanos para su atención.

Desde hace varios años, algunos de los mecanismos de democracia directa que existen se han aplicado en la Ciudad de México, específicamente las consultas. Mediante ellas, se ha puesto a consideración de los habitantes de esta entidad su opinión sobre algunos temas relevantes relacionados con la creación de obras públicas, la generación de bienes y servicios y la implementación de programas sociales. La capital del país ha sido una de las localidades más propensas para convocar a la realización de consultas populares, y desde 1995 cuenta con una ley sobre participación ciudadana (Ley de Participación Ciudadana del Distrito Federal) que le ha permitido llevar a cabo varios ejercicios con los más diversos resultados.

La pregunta que guía este trabajo es ¿cuáles son los rubros y los problemas públicos que han privilegiado los 
habitantes de la Ciudad de México para ser atendidos por sus autoridades mediante la instrumentación del mecanismo del presupuesto participativo?

Los titulares de las demarcaciones territoriales en la Ciudad de México han decidido, de manera unilateral y sin previa consulta a la ciudadanía, los temas de la agenda, las políticas públicas y la distribución del gasto. Si bien el electorado elige a sus gobernantes para que estos atiendan problemas, operen servicios y apliquen políticas públicas, gracias al presupuesto participativo ahora los habitantes de esta entidad pueden asumir una corresponsabilidad en la toma de decisiones, específicamente en la resolución de problemas públicos metropolitanos.

Ahora, si bien este mecanismo está diseñado para que los ciudadanos puedan sugerir temas que deben ser atendidos por sus autoridades locales, no se puede afirmar que este tipo de participación pueda llegar a ejercer un auténtico control social sobre el presupuesto que manejan los Gobiernos, ni tampoco se puede considerar que tiene lugar un mayor empoderamiento ciudadano, ni, menos aún, que este tipo de instrumentos ayude a que los habitantes introduzcan temas en la agenda de sus jefes delegacionales. No obstante, como se ha dicho, se trata de los primeros ejercicios de democracia directa a través de los cuales las instituciones del Gobierno local convocan a sus habitantes para que opinen sobre la definición de los problemas que consideran prioritarios.

Los retos que enfrenta la Ciudad de México son múltiples y complejos. Si bien las autoridades locales tienen una responsabilidad para definir y ejecutar políticas, recientemente están recurriendo a la consulta ciudadana para identificar las áreas que requieren mayor atención. El presupuesto participativo es un instrumento que proporciona a los Gobiernos locales un muestreo de las necesidades e inquietudes que su población desea que se atiendan de forma prioritaria. El mecanismo se ha utilizado en varias entidades federa- 
tivas, aunque ha sido en la Ciudad de México en donde se ha implementado mayor número de veces.

El presente trabajo se divide en cuatro secciones. La primera trata sobre los diferentes mecanismos de democracia directa, considerando especialmente la función y modalidad del presupuesto participativo. En la segunda parte, se aborda su aplicación en la Ciudad de México. En tercer lugar, se analiza la regulación legal que da sustento a este instrumento en la capital del país. Por último, se muestran los resultados derivados de este ejercicio en esta entidad durante el periodo de 2011 a 2017.

\section{Democracia directa, consulta popular y presupuesto participativo}

Una forma en la que se expresa la participación ciudadana es a través de la puesta en práctica de mecanismos de democracia directa. La intención de estos ejercicios es involucrar a la sociedad en la toma de decisiones para que pueda decidir sobre las acciones que han tomado o habrán de tomar sus autoridades. La convocatoria para llevar a cabo estos ejercicios a nivel nacional corresponde a los poderes Ejecutivo y Legislativo, mientras que a nivel subnacional la pueden hacer los gobernadores y los Congresos; en algunos países, también puede promoverlas la ciudadanía, y aunque si bien los ciudadanos son los principales actores con poder de convocatoria, generalmente los partidos políticos también asumen un papel proactivo para promoverlas.

Hasta el momento, el mecanismo más utilizado en varios países ha sido la consulta popular. Su función consiste en preguntar a la población sobre algún tema de interés público para que esta exprese su aceptación o rechazo hacia la propuesta de sus representantes, tomando en cuenta que así como hay temas relevantes que afectan a todo un país 
y tienen alcance nacional, también hay problemas que se reducen y se limitan a territorios muy focalizados.

Los mecanismos de democracia directa que se han utilizado son básicamente tres: 1) la consulta, 2) la iniciativa popular y 3) la revocación de mandato.

En el caso de la primera, se pueden distinguir dos subtipos. Primero está el plebiscito, que consiste en preguntar a la ciudadanía sobre proyectos o políticas públicas que todavía no entran en vigor, o bien, sobre medidas que ya fueron implementadas y generaron un debate público. Se trata de una consulta popular sobre materias políticas de gran importancia (Zovatto, 2008), y sirve también para que los ciudadanos decidan "entre aceptar o rechazar una propuesta que concierne a la soberanía" (Farley, 1986, p. 23). Una característica de esta figura es que el resultado no tiene un carácter vinculante, es decir, la ciudadanía no tiene la última palabra, únicamente emite una opinión.

El segundo subtipo de consulta es el referéndum, que consiste en "someter al voto popular directo leyes o actos administrativos para su ratificación" (Portillo, 2012, p. 37). Este instrumento confiere a la ciudadanía la potestad para la aprobación de cambios constitucionales (Zovatto, 2008), y también implica que "el pueblo puede participar en el proceso legislativo por medio de una consulta directa" (Butler y Ranney, 1978, p. 4). A diferencia del plebiscito, el referéndum sí tiene un carácter vinculante y no es puramente consultivo: el resultado tiene que ser necesariamente acatado por los Gobiernos independientemente de si están o no de acuerdo con la decisión emitida por la ciudadanía. Con el referéndum, la sociedad adquiere la potestad para decidir, lo que finalmente se puede traducir en un empoderamiento ciudadano, pues somete al veredicto del pueblo temas de interés nacional o subnacional.

Dado que con el referéndum el poder de decisión se transfiere de los Gobiernos a los ciudadanos, su instrumentación 
suele ser cuidadosa por parte de los actores que la promueven. En la gran mayoría de los casos, su implementación ha sido controlada por los propios Gobiernos, quienes deciden sobre las modalidades de la consulta, definen los temas y la fecha de su aplicación, formulan la pregunta, y deciden el porcentaje necesario de votos requeridos para su aprobación y si el resultado será obligatorio. Cuando esto sucede, están en posibilidad de manipular prácticamente todas las fases del proceso.

Una forma de contrarrestar el control de los Gobiernos sobre las consultas es cuando se instrumentan desde abajo, es decir, por la vía de la petición popular. En estos casos, la ciudadanía solicita que algunas leyes que ya fueron promulgadas o que se pretenden sancionar sean sometidas previamente a una consulta. En algunos países, ante "ciertas medidas que se van a convertir en ley, o cuando se va a modificar la constitución”, la aplicación de un referéndum es obligatoria (Butler y Raney, 1978, p. 23).

En el caso de la iniciativa popular, dicho instrumento le confiere a la ciudadanía la facultad para proponer frente al Poder Legislativo una iniciativa de ley o reforma. Este ejercicio propicia que dicha prerrogativa no recaiga exclusivamente en el Poder Ejecutivo o el Legislativo, lo que implica que los representantes populares no sean los únicos actores que tienen la competencia para proponer iniciativas de leyes. Con la iniciativa popular,

los ciudadanos pueden formular una petición para obligar a que ciertas medidas no contempladas en la agenda legislativa sean sometidas a la aprobación directa del electorado. En caso de que la medida sea aprobada en referéndum, tendrá fuerza de ley, aunque el Gobierno se oponga (Butler y Raney, 1978, p. 24).

Por último, se encuentra la revocación de mandato. Esta modalidad permite que la sociedad decida sobre la conti- 
nuidad o remoción de algún representante electo antes de que concluya formalmente su periodo de gobierno (García, 2006). En el mundo, este ejercicio se ha instrumentado básicamente a nivel subnacional y con mucho menos frecuencia a nivel nacional. Se trata de

una variante invertida de la elección de gobernantes, pues a partir de una petición popular que debe reunir ciertos requisitos (un número determinado de firmas y un porcentaje de votación), se somete a consideración de los votantes la posible remoción de un representante electo antes del plazo determinado por la ley (Prud'homme, 20I2, p. 25).

La interrupción de mandato que este instrumento permite puede alcanzar tanto a titulares del Gobierno como a legisladores, al dejar sin efecto su potestad para seguir ejerciendo el cargo.

Como se adelantaba antes, es importante señalar que todos estos mecanismos de democracia directa no sólo promueven la participación política, sino que también pueden empoderar al ciudadano, dado que a través de ellos este adquiere una corresponsabilidad en la toma de decisiones públicas una vez que decide tener voz en el debate y en la definición de políticas. De igual forma, estos mecanismos le permiten intervenir en la promoción de iniciativas de leyes, introducir temas en la agenda de los Gobiernos y, también, otorgar o negar un voto de confianza a sus representantes populares.

Alicia Lissidini (2015) elaboró una tipología sobre los mecanismos de democracia directa en donde distingue diferentes formas. En principio, la autora señala dos modalidades de democracia directa con base en los actores o instituciones con capacidad para convocar los mecanismos: los Poderes Ejecutivos o Legislativos, ya sea a nivel federal o local, y los ciudadanos. Si la propuesta proviene de los 
primeros, la consulta popular adquiere mayor importancia cuando tiene un carácter vinculante.

Por otro lado, si la iniciativa proviene de algún sector de la sociedad civil organizada, la consulta puede asumir dos formas: por un lado, un carácter proactivo, si promueve leyes o si decide sobre algún tema; y por otro, un carácter reactivo, si tiene la intención de derogar alguna ley que ya entró o puede entrar en vigor, o bien, si revoca el mandato de algún representante electo y lo separa del cargo antes de que concluya su periodo de gobierno (Figura 1 ).

Figura 1. Tipología de los mecanismos de democracia directa

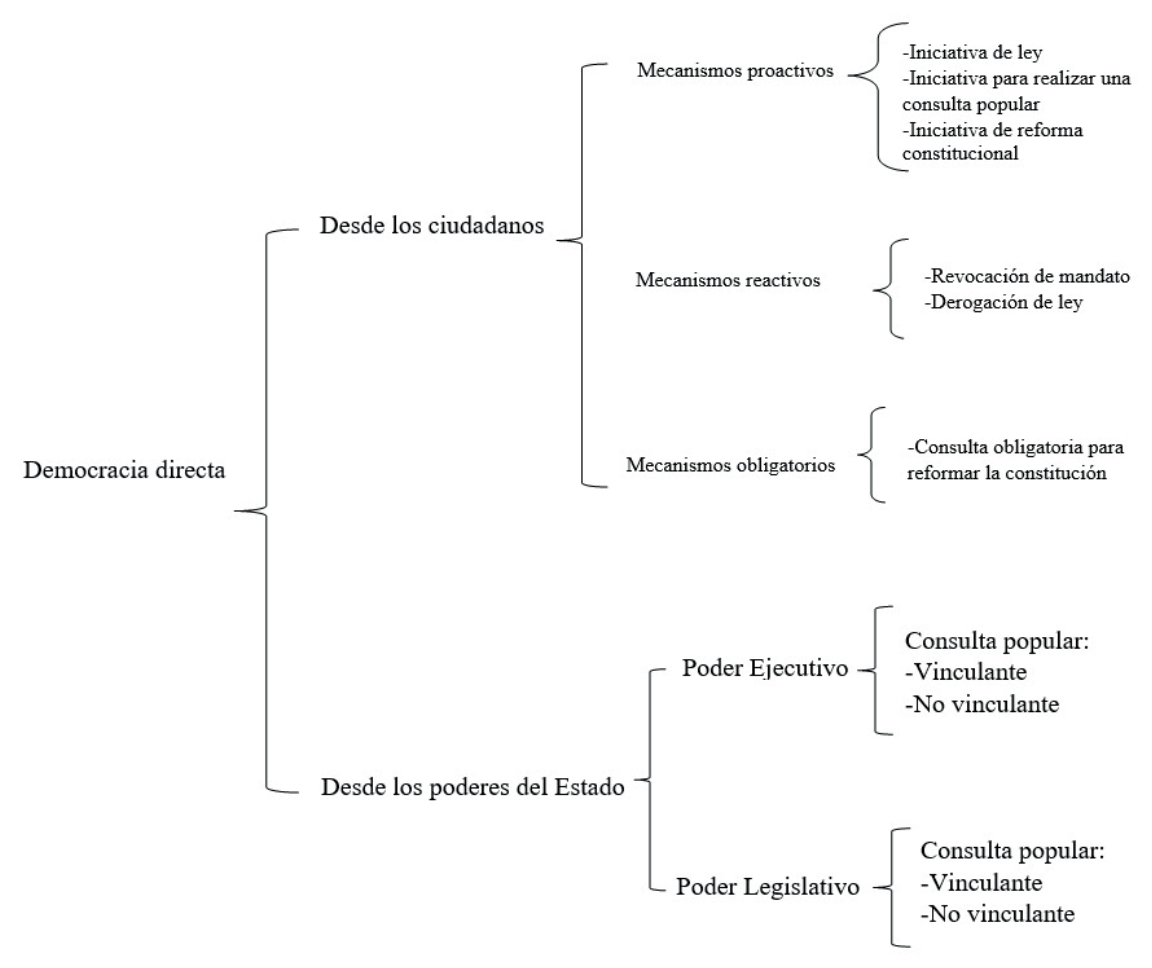

Fuente: Lissidini (2015, p. 147). 
Cabe señalar que los Poderes Ejecutivos se han convertido en activos promotores de las consultas populares. Entre las causas de ello se pueden mencionar:

1) Primero, los presidentes y los gobernadores tienen como una de sus facultades constitucionales el poder de convocatoria;

2) Segundo, los mandatarios recurren a las consultas populares cuando se produce un desacuerdo entre Ejecutivos y Congresos al momento de tomar una decisión, "de aquí que se somete a consideración de los ciudadanos el tema para que se pronuncien en uno u otro sentido" (Escamilla y Sánchez, 2016, p. 118);

3) Tercero, los Ejecutivos ven en la consulta popular un instrumento que les permite obtener el apoyo sobre algunas de sus decisiones, por lo que recurren al pueblo para buscar legitimarlas.

Los gobernantes no son actores exclusivos en la promoción de consultas populares, pero sí son los más propensos para convocarlas. Esto no ha ocurrido con los Poderes Legislativos, que no se han distinguido por fomentar los mecanismos de democracia directa, ni por someter a consideración de la sociedad algunos temas de interés nacional (Lissidini, 2015, p. 146). Esto es así porque con la consulta popular los legisladores dejan de tomar ciertas decisiones al transferirse esta potestad a la ciudadanía. En algunos países, las constituciones confieren a la ciudadanía el derecho para convocar a una consulta popular, y cuando es así, las reglas que definen estos ejercicios no son restrictivas ni excluyentes, dado que la facultad para convocar no se restringe a ni es exclusiva de las instituciones.

Ahora bien, uno de los mecanismos de democracia directa que se ha usado desde 1989 es el presupuesto participativo. La función de este ejercicio consiste en convocar a los habitantes de una demarcación territorial o municipio 
para que seleccionen, dentro de un conjunto de asignaturas propuestas por sus autoridades, las áreas administrativas que deben ser atendidas en el corto plazo. La opinión de los ciudadanos se expresa a través de una consulta, y una vez que eligen los temas, sus Gobiernos destinan una parte del presupuesto que reciben a la atención de los rubros que han priorizado la mayoría de los participantes.

De igual forma, bajo el presupuesto participativo los ciudadanos también pueden proponer sus propios proyectos para que sean considerados en las consultas. Si los habitantes de las demarcaciones territoriales o municipios hacen uso de estas prerrogativas, pueden incidir, aunque de forma muy tangencial, en la definición de los problemas públicos que deben ser gestionados. Estas consultas se han instrumentado básicamente a nivel subnacional. Los países latinoamericanos que la han practicado y adoptado en sus leyes son México, Argentina, Bolivia, Brasil, Chile, Colombia, Ecuador, Guatemala, Nicaragua, Perú, República Dominicana, El Salvador y Uruguay (Montecinos, 2014, p. 357).

A pesar de que estos trece países del continente ya han tenido algunas experiencias en la materia, su implementación todavía no se ha consolidado como una práctica recurrente. En algunos casos, se han cumplido satisfactoriamente las metas propuestas, mientras que otras implementaciones no han sido tan exitosas. La organización de las consultas puede ser transparente y legal, aunque también están propensas a la manipulación por parte de las autoridades. Su ejecución no está exenta de distorsiones, pero la eficacia del proceso depende de una serie de factores de orden político, burocrático, territorial, financiero, legal y cultural. Goldfrank (2006) y Bastida (2011) han ponderando algunos elementos que pueden influir en el resultado de estos ejercicios (Tabla 1). 


\section{Tabla 1. Factores de éxito, fracaso y manipulación} de los presupuestos participativos

Factores de éxito

Voluntad politica: los alcaldes encargados de instrumentar el presupuesto participativo deben estar comprometidos con la apertura de canales que permitan la participación ciudadana. Capital social: la comunidad local debe tener asociaciones civiles dispuestas a participar en los asuntos municipales.

Personal competente: la administración municipal debe contar con empleados técnicamente calificados.

Tamaño reducido: el municipio no debe ser tan grande que desaliente la acción colectiva.

Recursos suficientes: los Gobiernos municipales deben contar con fondos suficientes para la ejecución de proyectos públicos y de programas sociales.

Plataforma legal: las leyes deben incentivar la participación ciudadana.

Descentralización política: los alcaldes y concejales deben haber sido electos por medio de procesos democráticos.

Fuente: Goldfrank (2006, p. 7) y Bastida (2011, pp. 247-248).
Factores de fracaso o manipulación

El individualismo: hay riesgos como las actitudes individualistas y los enfrentamientos entre los participantes, lo que deja de lado su objetivo de transformación social.

El doble riesgo: la desviación del presupuesto y el surgimiento del clientelismo con todas sus consecuencias opuestas a la democracia.

El debilitamiento de las justas reivindicaciones de transformación social: los Gobiernos utilizan el presupuesto participativo no para provecho propio, pero sí de forma institucionalmente interesada, en un contexto en que las necesidades colectivas son grandes, justificadas y urgentes; además, los caudales municipales son escasos, por lo que las autoridades pueden sentirse tentadas a moderar la atención de las demandas de la ciudadanía. 
Como es visible en la Tabla 1, para que el ejercicio del presupuesto participativo pueda alcanzar la mayoría de sus objetivos (convocatoria, debates y presentación de proyectos ciudadanos, elección de rubros, asignación de presupuesto, ejecución de programas y evaluación) deben cumplirse una serie de condiciones.

En la parte política, se requiere compromiso por parte de las autoridades para incluir a la ciudadanía en la toma de decisiones y en la definición de problemas regionales que deben atenderse. En lo que se refiere al capital social, se requieren bases ciudadanas organizadas y dispuestas a participar. En cuanto al personal competente, la capacidad y profesionalización de las burocracias juega un papel central en aras de alcanzar los objetivos. Sobre el tamaño del territorio, estos ejercicios generalmente se aplican en demarcaciones no muy extensas (municipios, alcaldías, delegaciones políticas). En lo que se refiere a la disponibilidad de los recursos financieros, es necesario que el porcentaje del presupuesto designado para la atención de las áreas seleccionadas, si bien sea marginal, esté disponible. En cuanto a la parte legal, los marcos normativos deben regular las funciones y las responsabilidades de los actores involucrados en cada una de las fases del proceso. Sobre la descentralización política, se tienen que cumplir algunos requisitos mínimos para que los Gobiernos locales puedan actuar con cierta autonomía respecto del Gobierno central.

Por último, se habla de que es posible una manipulación por parte de las autoridades, pues estas pueden utilizar este instrumento para promover la organización y la movilización de clientelas con fines partidistas y electorales. De igual forma, la ley le confiere a los gobernantes las suficientes facultades para intervenir de manera amplia en todas las fases del proceso, de aquí que puedan incidir en la organización y el resultado final de la consulta. Finalmente, otro riesgo que distorsiona este ejercicio tiene que ver con la falta 
de transparencia, pues la opacidad en el manejo de recursos es una práctica común cuando las contralorías o la ciudadanía no cumplen con su papel de vigilantes y fiscalizadores.

En resumen, dentro del conjunto de mecanismos de democracia directa establecidos en los diferentes países de Latinoamérica, el presupuesto participativo ha permitido a los ciudadanos asumir una corresponsabilidad en la definición de temas y problemas públicos que deben ser atendidos de manera prioritaria por sus autoridades. Dado que se trata de una variante de la consulta diseñada para que los habitantes de una demarcación territorial seleccionen algunas áreas que demandan atención urgente, si el instrumento es ejecutado de forma correcta la población puede reorientar una parte mínima del gasto hacia la atención de ciertos rubros, proponer sus propios proyectos y, también, emitir una opinón para jerarquizar algunos de los temas de la agenda de sus Gobiernos.

\section{Las modalidades legales del presupuesto participativo en México}

El primer país que implementó una consulta relacionada con el presupuesto participativo fue Brasil, en 1989, en la ciudad de Porto Alegre. ${ }^{1}$ El ejercicio tuvo lugar durante el mandato de Olívio Dutra, del Partido dos Trabalhadores (Rendón, 2004, p. 10). La aplicación de este instrumento derivó en una medida gubernamental importante: aumentar el $50 \%$ de los fondos de la alcaldía a través de un proyecto de reforma tributaria del impuesto predial y territorial urbano (Freitas, 2006, p. 5). La política aprobada pretendía aumentar el gasto para atender problemas relacionados con los servicios públicos.

I. Sobre las características del modelo originario del presupuesto participativo en Brasil, véase: Rendón (2004). 
La intrumentación de la consulta fue novedosa, y permitió involucrar a la ciudadanía en la definición de los problemas de gestión metropolitana. El proceso de Porto Alegre esbozó un primer modelo de instrumentación del ejercicio, y en los siguientes años esta experiencia se extendería a otras ciudades y regiones de Europa y del continente americano.

En México, el presupuesto participativo se puso en práctica a nivel subnacional por primera ocasión en el año 2000, en el municipio de Santa Catarina, Nuevo León. Posteriormente lo implementaron algunas regiones de Jalisco, el Estado de México y las delegaciones de la Ciudad de México. Si bien se ha utilizado pocas veces, sus principales promotores han sido el Partido de la Revolución Democrática (PRD), el Partido Acción Nacional (PAN), el Partido Revolucionario Institucional (PRI) y Movimiento Ciudadano (MC). Algunos de los problemas en su ejecución en el país han sido la escasa difusión de la convocatoria por parte de las autoridades y la baja participación ciudadana, lo que ha impedido que su implementación sea recurrente.

Tras el ya mencionado primer ejercicio de presupuesto participativo en el estado de Nuevo Léon, en 2000, se realizaron los de la delegación Tlalpan, en la Ciudad de México, en el 2001; Ecatepec, en el Estado de México, en 2007; y la delegación Iztapalapa, de nuevo en la capital del país, en 2010. A partir de este último año, estas consultas se han realizado cada año en las dieciséis delegaciones políticas de la Ciudad de México (esto es, en un total de ocho ocasiones). En el caso del estado de Jalisco, algunos municipios los han instrumentado en 2011, 2013, 2015 y 2017.

La Tabla 2 pondera algunas características de los ejercicios iniciales de presupuesto participativo realizados entre 2000 y 2011 , antes de que comenzaran a utilizarse de forma más recurrente. 


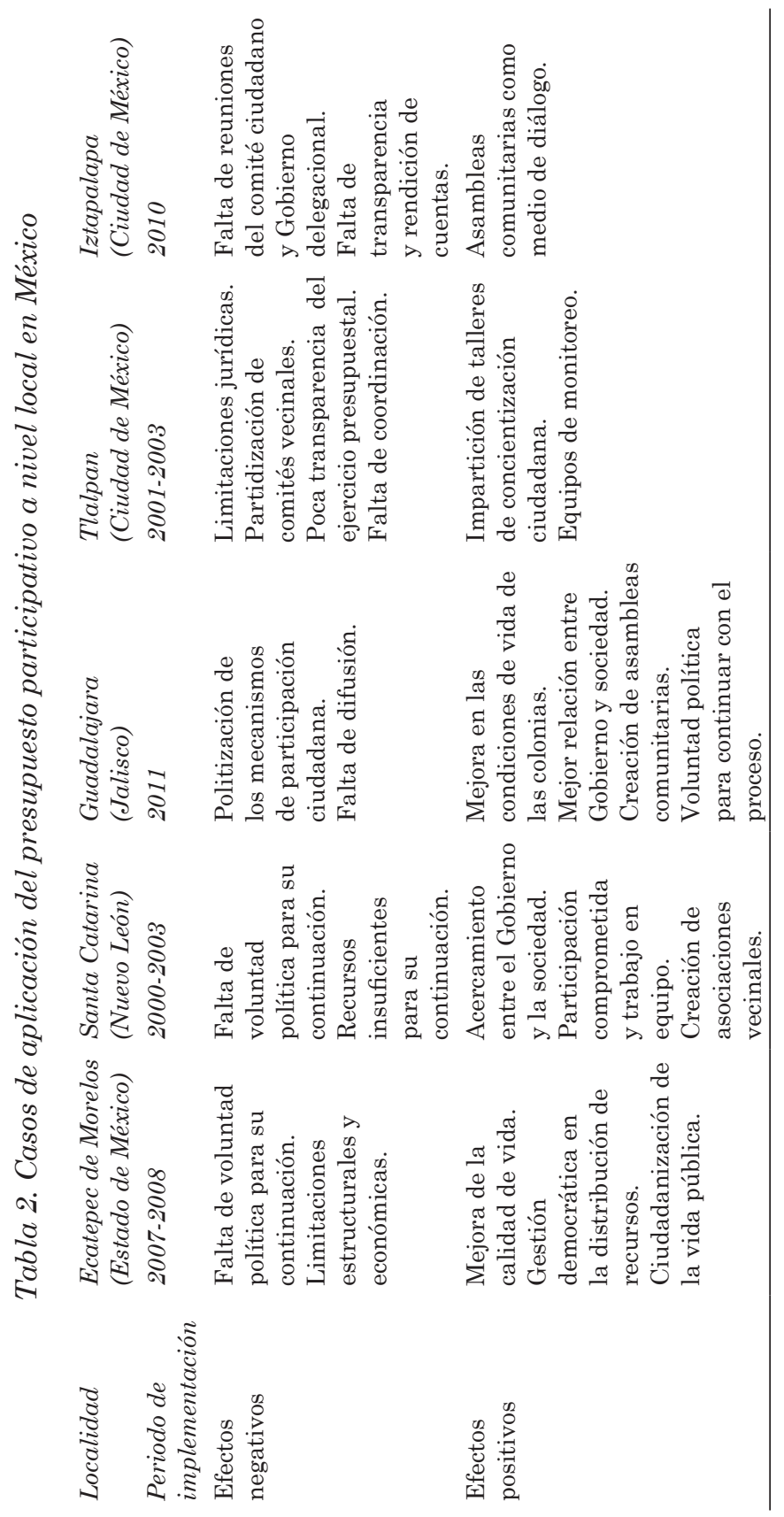




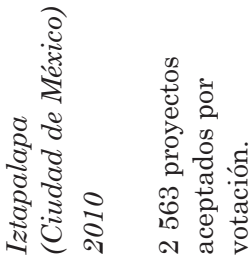

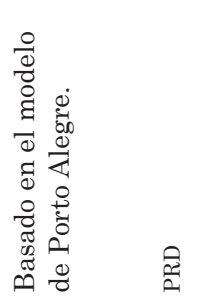

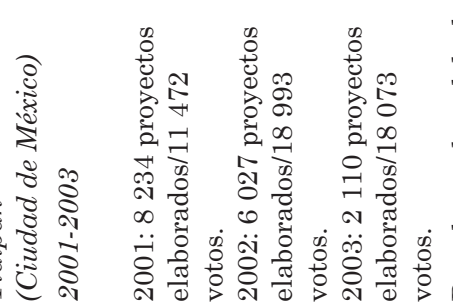

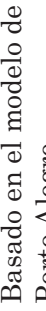

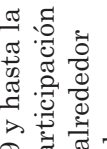

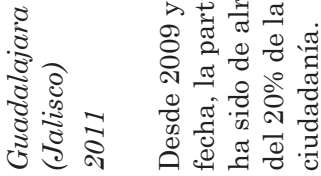

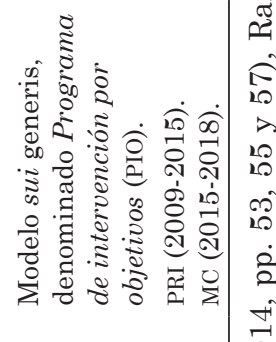

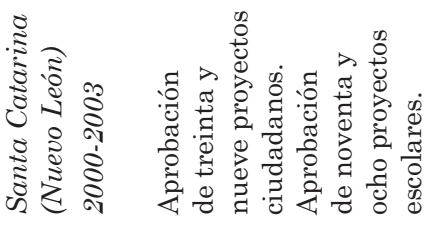

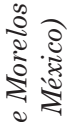

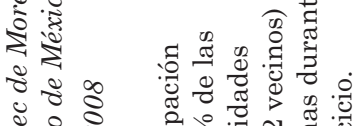

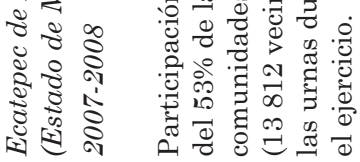

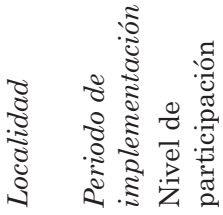

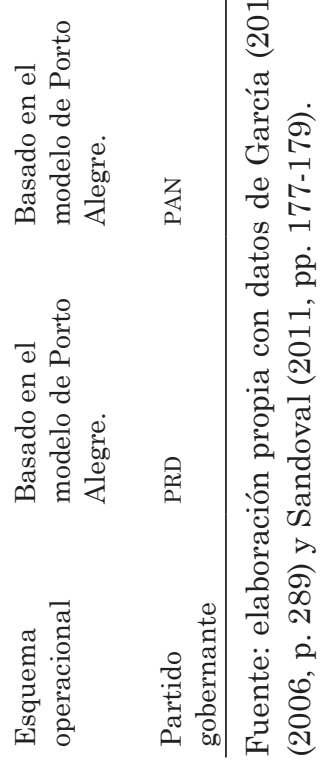


Los problemas que ha enfrentado la instrumentación del presupuesto participativo en las diferentes delegaciones políticas o municipios de estas entidades federativas son diversos. Por ejemplo, en la Ciudad de México, ha sido una constante la falta de transparencia y rendición de cuentas de las autoridades en el uso de recursos. En el Estado de México y Nuevo León, la dificultad ha radicado en la falta de voluntad y compromiso por parte de los alcaldes para convocar de manera más recurrente al ejercicio.

De igual forma, el mecanismo ha generado propensión a que las autoridades organicen redes y estructuras clientelares que son movilizadas como bases de apoyo partidistas durante periodos electorales, práctica que tergiversa la intención original con la que fue concebido el presupuesto participativo.

A pesar de estos factores, se ha logrado, aunque sea de manera incipiente, establecer puntos de contacto entre la ciudadanía y los Gobiernos locales, y también se han organizado asambleas comunitarias y se han difundido programas de concientización a raíz de estos ejercicios de democracia ciudadana.

Como se dijo en la introducción, en la Ciudad de México, desde 1995 se elaboró una ley de participación ciudadana, que ha permitido realizar varias consultas con los más diversos tópicos. En el caso del presupuesto participativo, su figura legal fue introducida en 2010. En la ley al respecto, se establecen las reglas de operación y los procedimientos, así como se delimitan las facultades y las funciones de las diferentes instancias (órganos legislativo y de Gobierno, instituciones electorales y organizaciones sociales) que conducen la organización, ejecución, vigilancia y evaluación del proceso.

El artículo 83 de la Ley de Participación Ciudadana del Distrito Federal (ahora Ciudad de México) reconoce al presupuesto participativo como un mecanismo en el cual los 
ciudadanos deciden respecto a la forma en que se aplican los recursos en proyectos específicos en las colonias y pueblos originarios en que se divide el territorio del DF, a través de un equivalente al $5 \%$ del total de los recursos del presupuesto anual de las delegaciones.

La ley ha sido modificada en cuatro ocasiones. En 2011, se estableció que anualmente se convocará a una consulta ciudadana que se realizará el segundo domingo de noviembre para definir los proyectos en los que se aplicará el presupuesto participativo; además, el Instituto Electoral de la Ciudad de México (IECM) se convirtió en la autoridad facultada para convocar, organizar y computar el resultado del ejercicio. ${ }^{2}$

En 2013, la ley se modificó para que se pudieran realizar de manera simultánea las elecciones de los Comités Ciudadanos y los Consejos de los Pueblos, así como una consulta relacionada con el presupuesto participativo.

En 2015, se aumentó el monto del presupuesto delegacional asignado a este ejercicio, del 3\% al 5\%. En la misma reforma, se ampliaron los rubros que pueden seleccionar los ciudadanos (Tabla 3), ${ }^{3}$ además de que se le otorgó al presupuesto participativo un carácter vinculante.

En 2016, se estableció que la Contraloría General y las Contralorías Internas de las diferentes delegaciones políticas serían las autoridades facultadas para auditar y sancionar el uso de los recursos destinados al presupuesto participativo.

2. La participación del órgano electoral tiene la intención de otorgarle mayor legitimidad al ejercicio del presupuesto participativo.Su intervención para organizar cada una de las etapas del proceso es clave si se pretende que la consulta cumpla con los principios de legalidad, transparencia y autonomía.

3. Inicialmente, se consideraron como áreas de atención prioritarias las obras y los servicios públicos, la creación de infraestructura y la prevención del delito. Esto mostraba que la asignación de bienes y servicios y la seguridad pública eran considerados problemas prioritarios por resolver. Posteriormente, se agregaron rubros como la promoción de actividades recreativas y culturales, además del equipamiento.

\section{4}


Tabla 3. Modificaciones en los rubros del presupuesto participativo de la Ciudad de México

\begin{tabular}{lll}
$\begin{array}{l}2010 \\
\text { Obras y servicios } \\
\text { públicos }\end{array}$ & $\begin{array}{l}2011 \\
\text { Equipamiento } \\
\text { Enfraestructura urbana }\end{array}$ & $\begin{array}{l}2013 \\
\text { Equipamiento }\end{array}$ \\
& Infraestructura & $\begin{array}{l}\text { Promoción de } \\
\text { actividades } \\
\text { recreativas, deportivas } \\
\text { Prevención del delito }\end{array}$ \\
& $\begin{array}{l}\text { Obras y servicios } \\
\text { públicos } \\
\text { Prevención del delito }\end{array}$ & $\begin{array}{l}\text { Infraestructura urbana } \\
\text { Prevención del delito } \\
\end{array}$ \\
& & $\begin{array}{l}\text { Obras y servicios } \\
\text { públicos }\end{array}$ \\
\hline
\end{tabular}

Fuente: Gómez Tagle (2017, pp. 17-18).

En la organización, ejecución y evaluación del presupuesto participativo en la Ciudad de México, intervienen una serie de instancias tanto institucionales como sociales. En cuanto a los primeros, participan el jefe de Gobierno de la Ciudad de México, la Asamblea Legislativa, los jefes delegacionales, el IECM, la Contraloría General y las Contralorías Internas de cada delegación. Otras instancias del Gobierno capitalino que apoyan su instrumentación son la Dirección General Jurídica y de Gobierno, la Dirección General de Administración, la Dirección General de Obras y Desarrollo Urbano, la Dirección General de Servicios Urbanos y la Dirección General de Desarrollo Social. En el caso de los actores de la sociedad civil organizada que participan están los Comités Vecinales y los representantes de manzana.

La Ley de Participación Ciudadana establece las funciones y las competencias de cada órgano en las diferentes fases del proceso. El involucramiento de los habitantes de las demarcaciones territoriales es un factor clave: su participación no se limita a decidir temas y proponer proyectos, también están facultados para fungir como vigilantes del 
ejercicio en su conjunto. La Tabla 4 muestra a los actores involucrados, sus competencias y sus facultades en la ejecución del instrumento.

De acuerdo con esta distribución de competencias y obligaciones, en lo que se refiere al Ejecutivo local, las funciones del jefe de Gobierno de la Ciudad de México consisten en incluir en el apartado de las delegaciones políticas del presupuesto de egresos los montos y los rubros destinados al presupuesto participativo, así como tomar en cuenta los resultados de las consultas para incluir los temas seleccionados en el siguiente proyecto de egresos.

En el caso del Poder Legislativo, la Asamblea Legislativa de la Ciudad de México debe aprobar y vigilar los recursos que habrán de utilizarse derivados de este ejercicio, mientras que los jefes delegacionales tienen la obligación de contemplar en los programas operativos y en los anteproyectos anuales del presupuesto de egresos el 5\% del total presupuestal que reciben para ejecutar los programas; estos recursos deberán ejercerlos antes de que concluya el año fiscal. Otra de sus funciones es otorgar asesorías a los ciudadanos para el registro de proyectos.

A su vez, el IECM, en su calidad de órgano electoral autónomo, emite la convocatoria, asesora y capacita a los integrantes de los comités ciudadanos, realiza el cómputo de los votos y valida el resultado del ejercicio. En lo que se refiere a la participación de las organizaciones sociales, los Comités Ciudadanos se involucran directamente en la fase de planeación de los programas y políticas, mientras que los representantes de manzana únicamente emiten una opinión sobre los proyectos.

En cuanto a las fases del presupuesto participativo, se trata de un proceso que se compone de cinco etapas. En la primera, el IECM emite la convocatoria; en la segunda, se registran y se preseleccionan los proyectos; en la tercera, se difunden estos documentos entre los colonos para su 


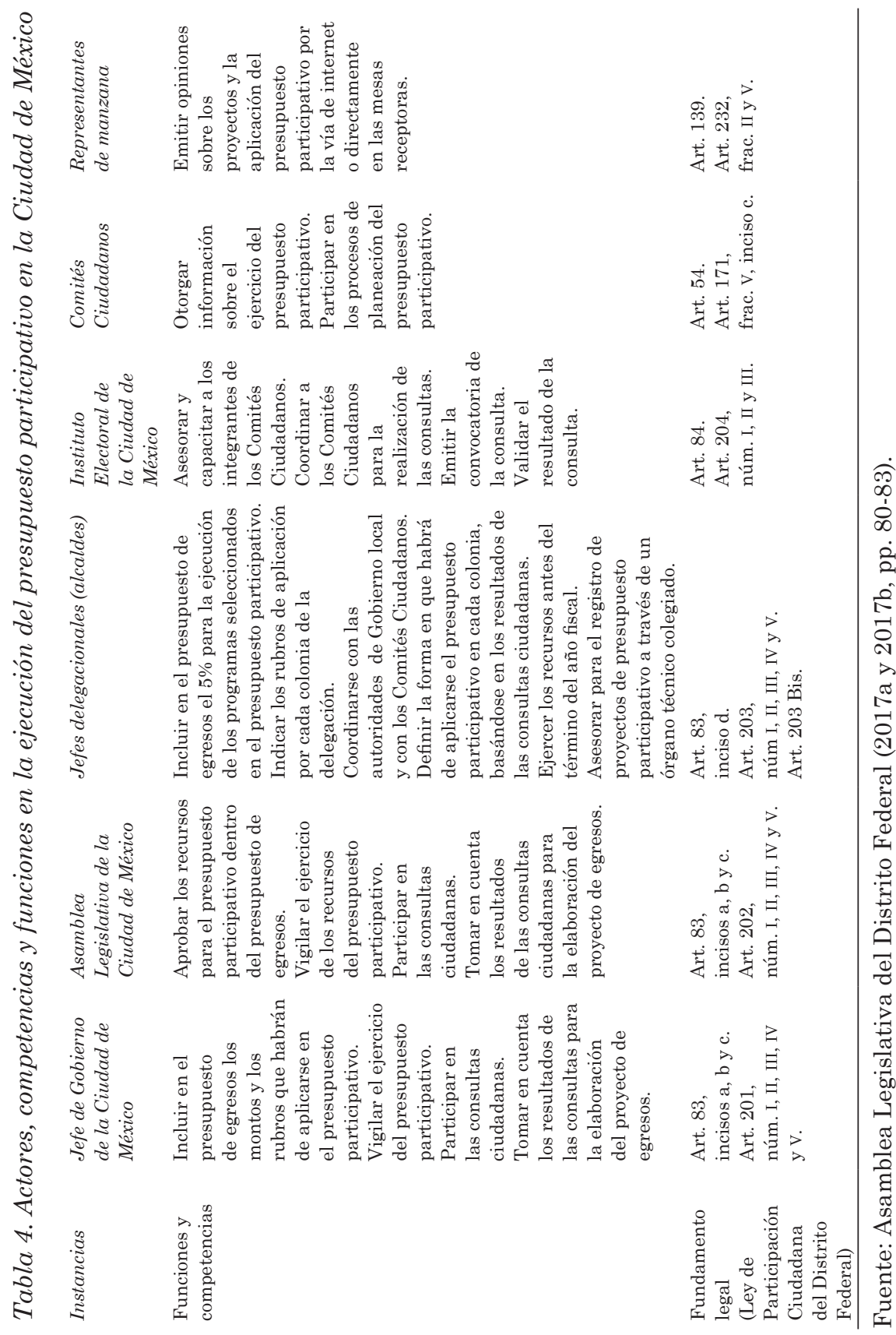


discusión; en la cuarta, se realiza la consulta una vez que los vecinos emiten su opinión a través de internet o directamente en las mesas receptoras; y en la quinta, los Consejos Ciudadanos y los Consejos de Pueblos validan y entregan los resultados.

Una vez que se realiza la consulta y se dan a conocer los proyectos ganadores, los rubros seleccionados pasan a ser contemplados en el plan de gastos del Gobierno de la Ciudad de México, y las instancias financieras se encargan de definir y asignar los recursos que serán utilizados. Para esto último, la Secretaría de Finanzas de la ciudad elabora un proyecto general que el jefe de Gobierno presenta ante la Asamblea Legislativa, la cual lo discute y aprueba. La Tabla 5 sintetiza cada una de las fases.

Los colonos que participan de forma organizada en este proceso pueden dar seguimiento y monitorear cada una de sus etapas para vigilar las acciones de sus autoridades. Si los ciudadanos están comprometidos con estas funciones, pueden ejercer una especie de control social sobre la forma en que las autoridades gastan un porcentaje del total de los recursos públicos que reciben. Aunque se trata de una parte mínima del presupuesto, el mecanismo significa que los ciudadanos ya pueden orientar cierta cantidad de dinero para la atención de los problemas que consideran prioritarios. Por ello, su intervención es clave en tres fases: 1) el debate y la propuesta de proyectos, 2) la decisión sobre los rubros que deberán ser atendidos por sus autoridades y 3) la vigilancia y evaluación del ejercicio en su conjunto.

\section{Aplicación y resultados del presupuesto participativo en la Ciudad de México}

En la Ciudad de México, se ha realizado un total de ocho consultas (de 2010 a 2017) relacionadas con el presupuesto participativo. Por principio, cabe resaltar que los niveles de 


\section{Tabla 5. Etapas del presupuesto participativo}

\begin{tabular}{|c|c|c|}
\hline Etapa & Fechas & Actividad \\
\hline $\begin{array}{l}\text { Emisión } \\
\text { de la } \\
\text { convocatoria }\end{array}$ & Abril & $\begin{array}{l}\text { El Consejo General del IECM aprueba la } \\
\text { convocatoria y esta es difundida en los } \\
\text { medios de comunicación. }\end{array}$ \\
\hline $\begin{array}{l}\text { Registro de } \\
\text { proyectos }\end{array}$ & Abril-julio & $\begin{array}{l}\text { Se inicia con la entrega de presentación } \\
\text { de proyectos, con el siguiente } \\
\text { procedimiento: }\end{array}$ \\
\hline & & $\begin{array}{l}\text { 1. Recepción de solicitudes en la Dirección } \\
\text { Distrital. } \\
\text { 2. Remisión de proyectos a la jefatura } \\
\text { delegacional. } \\
\text { 3. La Delegación emite su opinión sobre } \\
\text { la viabilidad de cada propuesta. } \\
\text { 4. Preselección de proyectos. }\end{array}$ \\
\hline Difusión de & Agosto & Los integrantes de los Consejos \\
\hline proyectos & & $\begin{array}{l}\text { Ciudadanos organizan foros informativos } \\
\text { en donde se dan a conocer sus proyectos. }\end{array}$ \\
\hline $\begin{array}{l}\text { Jornada de } \\
\text { emisión de } \\
\text { opinión }\end{array}$ & $\begin{array}{l}\text { Última } \\
\text { semana } \\
\text { de agosto } \\
\text { y primera } \\
\text { semana de } \\
\text { septiembre }\end{array}$ & $\begin{array}{l}\text { Los ciudadanos dan a conocer su opinión } \\
\text { sobre los proyectos de presupuesto } \\
\text { participativo para su colonia o pueblo, a } \\
\text { través del sitio de internet o de las mesas } \\
\text { receptoras. }\end{array}$ \\
\hline $\begin{array}{l}\text { Validación } \\
\text { y entrega de } \\
\text { resultados }\end{array}$ & Septiembre & $\begin{array}{l}\text { 1. Se invita a los Consejos Ciudadanos y a } \\
\text { los Consejos de Pueblos para la validación } \\
\text { de los resultados. } \\
\text { 2. El IECM manda la documentación } \\
\text { respectiva al jefe de Gobierno, a las } \\
\text { comisiones de Presupuesto y Cuenta } \\
\text { Pública, a la de Hacienda y a la } \\
\text { de Participación Ciudadana de la } \\
\text { Asamblea Legislativa, así como a los } \\
\text { jefes delegacionales y a los Consejos } \\
\text { Ciudadanos, esto para su consideración } \\
\text { en el proyecto de egresos. }\end{array}$ \\
\hline
\end{tabular}

Fuente: elaboración propia con base en Instituto Electoral del Distrito Federal (2014). 
participación ciudadana muestran índices bajos (aproximadamente 5\%), y que únicamente en dos de los ocho procesos se han registrado niveles relativamente altos: en 2013, la afluencia fue de $11.96 \%$, y en 2016 acudieron a emitir su opinión el 10.9\% de los ciudadanos, lo que puede deberse a que en dichos años se celebraron elecciones concurrentes para elegir a los integrantes tanto de los Consejos Ciudadanos como de los Consejos de Pueblos, lo que a su vez pudo propiciar un mayor interés ciudadano por involucrarse en estos procesos.

En este rubro, puede afirmarse que hay poco interés entre colonos y vecinos por participar. Los índices de afluencia aumentan cuando las consultas y las elecciones se llevan a cabo de manera simultánea. Para subsanar este déficit, las autoridades han puesto mayor énfasis en dos aspectos: han ampliado la difusión y han aumentado los programas de capacitación. A pesar de estas medidas, no se ha propiciado un mayor interés ciudadano. La Figura 2 muestra los niveles de participación en estos ejercicios en la Ciudad de México en el periodo que va de 2011 a 2017.

Si se considera la participación desagregada en cada una de las delegaciones políticas de la capital, se pueden observar algunas diferencias. En demarcaciones como Azcapotzalco e Iztacalco, los habitantes tienden a participar con mayor frecuencia ( $10.02 \%$ y $6.46 \%$, respectivamente), en niveles que contrastan con territorios como Benito Juárez, Cuauhtémoc y Tláhuac, donde la afluencia apenas alcanza un $2 \%$ o $3 \%$. En el resto de delegaciones, oscila entre $4 \%$ y $5 \%$. Aun considerando que el ejercicio del presupuesto participativo en México, específicamente en la capital del país, es relativamente reciente, llama nuevamente la atención el escaso interés e involucramiento de los ciudadanos en estos procesos. 
Figura 2. Niveles de participación ciudadana en los ejercicios de presupuesto participativo en la Ciudad de México (2011-2017)

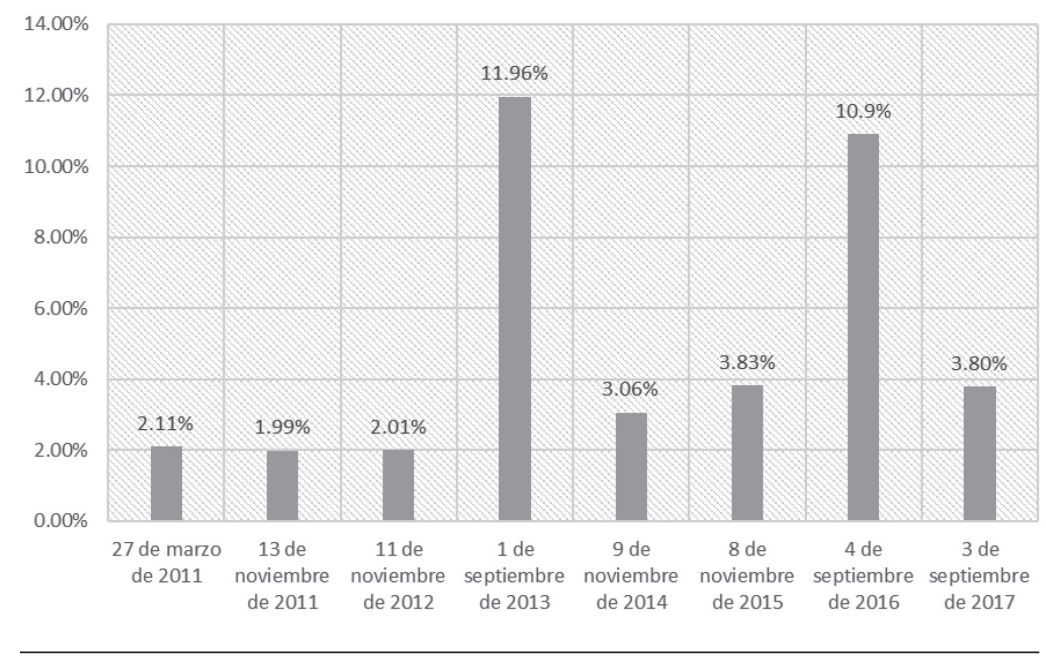

Fuente: elaboración propia con base en Instituto Electoral del Distrito Federal (s/f).

En lo que se refiere a la cantidad de proyectos presentados por los colonos, cada año han aumentado las propuestas, aunque al mismo tiempo también ha crecido el número de proyectos que no son aceptados por el Comité Técnico Delegacional. Un problema es que los Comités Técnicos, órganos encargados de definir los temas, no han funcionado con la suficiente autonomía para seleccionar los rubros, sino que los jefes delegacionales mantienen una influencia considerable en esta etapa del proceso. De igual forma, se ha presentado una práctica que también tergiversa el procedimiento: existen grupos de ciudadanos que proponen proyectos y al mismo tiempo mantienen vínculos directos con las estructuras partidistas y las burocracias de las delegaciones políticas (Gómez Tagle, 2017, p. 46). Esto puede propiciar una desigual distribución de recursos, una elec- 
ción de rubros dirigida desde las autoridades, y decisiones basadas en intereses políticos.

Figura 3. Participación ciudadana en las consultas por delegación política (2011-2017)

\begin{tabular}{|c|c|c|c|c|c|c|c|c|c|}
\hline Delegación & $\begin{array}{l}\text { Mar } \\
2011\end{array}$ & $\begin{array}{l}\text { Nov } \\
2011\end{array}$ & $\begin{array}{l}\text { Nov } \\
2012\end{array}$ & $\begin{array}{l}\text { Sep } \\
2013\end{array}$ & $\begin{array}{l}\text { Nov } \\
2014\end{array}$ & $\begin{array}{l}\text { Nov } \\
2015\end{array}$ & $\begin{array}{l}\text { Sep } \\
2016\end{array}$ & $\begin{array}{l}\text { Sep } \\
2017\end{array}$ & $\begin{array}{c}\text { Total } \\
\text { promedio }\end{array}$ \\
\hline Álvaro Obregón & $3.48 \%$ & $2.77 \%$ & $2.47 \%$ & $12.27 \%$ & $5.30 \%$ & $3.58 \%$ & $12.65 \%$ & $3.74 \%$ & $5.78 \%$ \\
\hline Azcapotzalco & $1.94 \%$ & $2.12 \%$ & $1.89 \%$ & $10.38 \%$ & $2.98 \%$ & $2.47 \%$ & $9.31 \%$ & $1.49 \%$ & $10.02 \%$ \\
\hline Benito Juárez & $1.02 \%$ & $0.89 \%$ & $1.11 \%$ & $4.57 \%$ & $2.84 \%$ & $0.95 \%$ & $3.80 \%$ & $0.51 \%$ & $1.96 \%$ \\
\hline Coyoacán & $2.15 \%$ & $1.72 \%$ & $2.16 \%$ & $11.14 \%$ & $3.10 \%$ & $4.68 \%$ & $10.95 \%$ & $4.48 \%$ & $5.04 \%$ \\
\hline $\begin{array}{l}\text { Cuajimalpa de } \\
\text { Morelos }\end{array}$ & $2.17 \%$ & $1.97 \%$ & $1.76 \%$ & $11.95 \%$ & $2.62 \%$ & $2.20 \%$ & $11.83 \%$ & $3.45 \%$ & $4.47 \%$ \\
\hline Cuauhtémoc & $1.55 \%$ & $1.85 \%$ & $0.82 \%$ & $8.80 \%$ & $2.82 \%$ & $1.33 \%$ & $8.06 \%$ & $0.76 \%$ & $3.24 \%$ \\
\hline Gustavo A. Madero & $1.94 \%$ & $1.89 \%$ & $1.85 \%$ & $11.36 \%$ & $2.74 \%$ & $4.85 \%$ & $10.42 \%$ & $2.73 \%$ & $4.72 \%$ \\
\hline Iztacalco & $1.61 \%$ & $1.55 \%$ & $2.86 \%$ & $16.94 \%$ & $2.50 \%$ & $7.49 \%$ & $11.30 \%$ & $7.50 \%$ & $6.46 \%$ \\
\hline Iztapalapa & $1.99 \%$ & $1.67 \%$ & $2.14 \%$ & $15.20 \%$ & $2.54 \%$ & $5.46 \%$ & $11.45 \%$ & $2.35 \%$ & $5.35 \%$ \\
\hline $\begin{array}{l}\text { Magdalena } \\
\text { Contreras }\end{array}$ & $2.51 \%$ & $3.28 \%$ & $1.65 \%$ & $15.38 \%$ & $3.37 \%$ & $2.00 \%$ & $13.08 \%$ & $1.58 \%$ & $5.35 \%$ \\
\hline Miguel Hidalgo & $1.49 \%$ & $1.45 \%$ & $1.46 \%$ & $12.78 \%$ & $3.11 \%$ & $1.57 \%$ & $9.41 \%$ & $1.27 \%$ & $4.06 \%$ \\
\hline Milpa Alta & $3.30 \%$ & $5.43 \%$ & $4.48 \%$ & $12.59 \%$ & $2.31 \%$ & $3.67 \%$ & $8.61 \%$ & $1.30 \%$ & $5.21 \%$ \\
\hline Tlähuac & $2.31 \%$ & $1.56 \%$ & $1.66 \%$ & $9.30 \%$ & $2.22 \%$ & $3.35 \%$ & $5.51 \%$ & $1.11 \%$ & $3.37 \%$ \\
\hline Tlalpan & $2.72 \%$ & $2.24 \%$ & $2.33 \%$ & $10.10 \%$ & $2.60 \%$ & $2.27 \%$ & $8.60 \%$ & $1.52 \%$ & $4.04 \%$ \\
\hline $\begin{array}{l}\text { Venustiano } \\
\text { Carranza }\end{array}$ & $2.37 \%$ & $3.27 \%$ & $2.85 \%$ & $12.72 \%$ & $2.71 \%$ & $5.50 \%$ & $8.87 \%$ & $4.96 \%$ & $5.40 \%$ \\
\hline Xochimilco & $1.99 \%$ & $1.72 \%$ & $1.62 \%$ & $10.79 \%$ & $6.95 \%$ & $1.82 \%$ & $7.00 \%$ & $1.11 \%$ & $4.12 \%$ \\
\hline
\end{tabular}

Fuente: elaboración propia con base en Instituto Electoral del Distrito Federal (2014). 
Figura 4. Aceptación y rechazo de proyectos ciudadanos

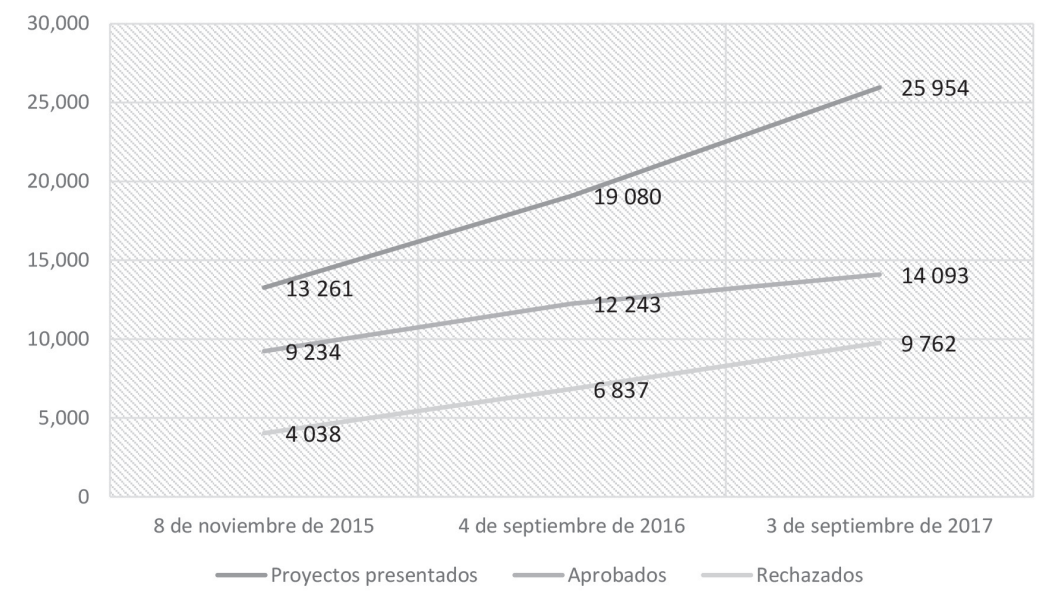

Fuente: elaboración propia con base en los datos arrojados por el Instituto Electoral de la Ciudad de México, según recurso de acceso a la información número IECM/SE/UT/577/2017, en poder del autor.

En cuanto a los rubros que han priorizado los ciudadanos en las consultas sobre el presupuesto participativo, la mayoría de las opiniones se ha orientado básicamente hacia la creación de obras e infraestructura, la generación de bienes y servicios, el equipamiento, la prevención del delito, así como el fomento de actividades recreativas, deportivas y culturales. De esto se desprende que se han privilegiado áreas como los servicios, la obra pública y el combate a la inseguridad en las colonias. La Figura 5 muestra la distribución de las opiniones en los rubros ya mencionados. 
Figura 5. Opiniones ciudadanas por rubro (2011-2017)

\begin{tabular}{|c|c|c|c|c|c|c|c|c|}
\hline Rubro & $\begin{array}{l}\text { Mar } \\
2011\end{array}$ & $\begin{array}{l}\text { Nov } \\
2011\end{array}$ & $\begin{array}{l}\text { Nov } \\
2012\end{array}$ & $\begin{array}{l}\text { Sep } \\
2013\end{array}$ & $\begin{array}{l}\text { Nov } \\
2014\end{array}$ & $\begin{array}{l}\text { Nov } \\
2015\end{array}$ & $\begin{array}{l}\text { Sep } \\
2016\end{array}$ & $\begin{array}{l}\text { Sep } \\
2017\end{array}$ \\
\hline Obras y servicios & 36190 & 32721 & 39307 & 108775 & 65991 & 65528 & 169600 & 62525 \\
\hline $\begin{array}{l}\text { Equipamiento e } \\
\text { infraestructura }\end{array}$ & 34523 & - & - & - & - & - & - & - \\
\hline Equipamiento & - & 23224 & 20712 & 23966 & 5287 & 50942 & 141312 & 49340 \\
\hline Infraestructura urbana & - & 44445 & 33912 & 162096 & 51234 & 92838 & 244283 & 14361 \\
\hline Prevención del delito & 66842 & 38805 & 47369 & 270390 & 35149 & 29000 & 123127 & 58330 \\
\hline $\begin{array}{c}\text { Actividades } \\
\text { recreativas, deportivas } \\
\text { y culturales }\end{array}$ & - & - & - & 165412 & 24158 & - & - & - \\
\hline $\begin{array}{l}\text { Actividades } \\
\text { recreativas }\end{array}$ & - & - & - & - & - & 8743 & 1182 & 5229 \\
\hline $\begin{array}{c}\text { Actividades } \\
\text { deportivas }\end{array}$ & - & - & - & - & - & 11426 & 839 & 2044 \\
\hline Actividades culturales & - & - & - & - & - & 10194 & 10473 & 1682 \\
\hline Otros & - & - & - & - & - & 1565 & 2350 & - \\
\hline No especificados & 1357 & 1194 & 3295 & 22063 & - & - & - & - \\
\hline Restantes & - & - & 300 & 4524 & 1202 & - & - & - \\
\hline Opiniones nulas & 3570 & - & - & 119684 & 5786 & 6768 & 71423 & - \\
\hline Total & 142482 & 140389 & 144895 & 876910 & 188807 & 277004 & 764589 & 193211 \\
\hline
\end{tabular}

Fuente: Instituto Electoral de la Ciudad de México (2014 y 2017).

De acuerdo a la Figura 5, los rubros de obras y servicios públicos, equipamiento y prevención del delito son los que han concentrado mayor votación en las consultas ciudadanas implementadas entre 2011 y 2017 . En el otro extremo, el que recibe menor cantidad de votos es el de las actividades recreativas, deportivas y culturales. Aunque hay problemas que son comunes a todas las demarcaciones territoriales, 
cada delegación política enfrenta sus retos particulares, de ahí que la selección de rubros por parte de los ciudadanos no sea homogénea.

\section{Conclusiones}

La aplicación del presupuesto participativo en la Ciudad de México se ha constituido en un mecanismo de democracia directa que ha permitido a los ciudadanos seleccionar políticas metropolitanas que serán atendidas por sus autoridades en el corto plazo. Si bien ya se considera la opinión de los habitantes de las demarcaciones territoriales, todavía no se puede afirmar que este tipo de ejercicios promueva una mayor participación política, ni tampoco que haya permitido ejercer un auténtico control social sobre una parte de los recursos que manejan las autoridades; menos aún es posible considerar que este mecanismo ha contribuido a un mayor empoderamiento ciudadano. En todo caso, el instrumento permite que los habitantes propongan un número reducido de rubros que se introducen en la agenda de los jefes delegacionales.

A pesar de esto, algunos grupos de ciudadanos ya han comenzado a asumir una corresponsabilidad en la definición de temas y problemas públicos que atañen a territorios muy focalizados, además de que ya pueden reorientar una parte del gasto hacia la atención de ciertos rubros que consideran urgentes de atender. Además, la intervención ciudadana es clave en tres fases, como se dijo en el presente artículo: 1) el debate y la propuesta de proyectos, 2) la decisión sobre algunos rubros que deberán ser atendidos por sus autoridades, y 3) la vigilancia y evaluación del ejercicio en su conjunto.

También, se ha señalado que en la ejecución del presupuesto participativo intervienen instituciones y funcionarios como la Jefatura de Gobierno, la Asamblea Legislativa, los jefes delegacionales, el IECM, la Contraloría General y las 
Contralorías Internas de cada delegación. Otras instancias que apoyan la instrumentación del presupuesto participativo son la Dirección General Jurídica y de Gobierno, la Dirección General de Administración, la Dirección General de Obras y Desarrollo Urbano, la Dirección General de Servicios Urbanos y la Dirección General de Desarrollo Social. En el caso de los actores de la sociedad civil organizada, participan los Comités Vecinales y los representantes de manzana.

En el presente artículo se revisó cómo la Ley de Participación Ciudadana del Distrito Federal le confiere a varios órganos del Gobierno de la Ciudad de México las suficientes facultades para intervenir de manera amplia las diferentes fases del proceso de estos ejercicios. Se dijo que la introducción de la figura legal del presupuesto participativo se estableció en 2010 en esta entidad, y ha sido modificada en cuatro ocasiones (2011, 2013, 2015 y 2016). Entre los principales cambios, se destacaron las facultades que se le atribuyeron al IECM para convocar, organizar y computar el resultado de las opiniones ciudadanas, así como el aumento en el monto del presupuesto asignado a este ejercicio de $3 \%$ a 5\%, lo que vino aparejado con la ampliación de los rubros que pueden seleccionar los ciudadanos.

Otra modificación que se resaltó durante la argumentación realizada es que se le otorgó a estas consultas un carácter vinculante, y que, de igual forma, se le dieron a la Contraloría General y las Contralorías Internas de las diferentes delegaciones políticas facultades para auditar y sancionar el uso de los recursos destinados al presupuesto participativo.

Como se dijo en el presente artículo, si bien esto último ya permite cierta vigilancia sobre el dinero que se gasta en la implementación de los diferentes programas, la fiscalización se encuentra todavía limitada porque las instancias encargadas de ejecutar las auditorias pertenecen al propio 
Gobierno, es decir, el control administrativo no lo ejerce un órgano autónomo, lo cual no permite practicar la transparencia y la rendición de cuentas. Este aspecto es importante si se considera que el presupuesto participativo está concebido para que los Gobiernos locales gasten recursos.

El porcentaje del presupuesto que los Gobiernos locales destinan a la atención de los rubros seleccionados por los ciudadanos todavía es mínimo. Si se considera que se trata de los primeros ejercicios, puede resultar razonable la cantidad, sin embargo, en la medida en que el instrumento se consolide como una práctica recurrente, los montos de los recursos pueden aumentar gradualmente, como ya ha venido ocurriendo.

Además, una revisión de estadísticas permitió detectar que durante las ocho ocasiones en que se han implementado en la Ciudad de México, las consultas se han caracterizado por un escaso interés por parte de la ciudadanía, aunque la participación aumenta ligeramente cuando la consulta es concurrente. Con excepción de la delegación Azcapotzalco, el resto de las demarcaciones territoriales muestra poco involucramiento por parte de sus habitantes. También debe considerarse que en los últimos años ha aumentado el número de proyectos aprobados que proponen los habitantes, y que los rubros que han recibido el mayor número de votos en las dieciséis delegaciones políticas de la capital han sido las obras y los servicios públicos, la creación de infraestructura y la prevención del delito.

Mientras que en otras entidades federativas la implementación del presupuesto participativo no ha sido recurrente debido a obstáculos políticos, administrativos y legales, en la Ciudad de México ha comenzado a practicarse de forma ininterrumpida desde el año 2011. Los retos que enfrentan las consultas sobre el presupuesto participativo tendrán que ser atendidos y resueltos tanto por las autoridades como por las organizaciones de colonos y vecinos. Algunos 
de los problemas más importantes que se han identificado son la falta de generación de un mayor interés por parte de los ciudadanos para emitir opiniones y la vigilancia ciudadana hacia las burocracias encargadas de implementar los programas.

Bibliografía
Asamblea Legislativa del Distrito Federal (2017a). Ley de Participación Ciudadana del Distrito Federal. Ciudad de México: ALDF.

Asamblea Legislativa del Distrito Federal (2017b). Constitución política de la Ciudad de México. Ciudad de México: ALDF.

Bastida, B. (20I I). "Riesgos de una utilización perversa del proceso de presupuesto participativo”, en J. Bou Geli (coord.), Refundar la democracia: presupuestos participativos en contextos diversos (pp. 240-248). Madrid: Atrapasueños.

Butler, D., y Ranney, A. (1978). Referendums: A Comparative Study of Practice and Theory. Washington: American Enterprise Institute for Public Policy Research.

Escamilla, A., y Sánchez, R. (20I6). “Las facultades constitucionales del Ejecutivo en América Latina: entre la concentración y la dispersión del poder". Estudios políticos, (37), III-I4I.

Farley, L. (1986). Plebiscite and Sovereignty:The Crisis of Political Illegitimacy. Colorado:West View Press.

Freitas, A. (2006). "La experiencia de democracia participativa en Porto Alegre”. Biblioteca Online de Ciências da Comunicação. Recuperado de: http://www.bocc.ubi.pt/ pag/freitas-andrea-experiencia-democracia.pdf

García, A. (2006). "La revocación de mandato: un breve acercamiento teórico". Quid iuris, I(I), 25-40.

García, F. (20I4). El presupuesto participativo de la Ciudad de México. ¿Participación ciudadana con resultados? México: UNAM. 
Goldfrank, B. (2006). "Los procesos de presupuesto parBibliografía ticipativo en América Latina: éxito, fracaso y cambio". Revista de ciencia política, XXVI(2), 3-28.

Gómez Tagle, S. (2017). Informe sobre las consultas de participación ciudadana en la Ciudad de México:Comités Ciudadanos, Consejos de los Pueblos y presupuesto participativo. México: El Colegio de México, IEDF.

Instituto Electoral de la Ciudad de México (20|4). Diseño de proyectos para el presupuesto participativo y proyectos exitosos. Recuperado de: https://www.dropbox.com/s/ wg24 I qtczsmhhxz/diseno_proyectos_elect.pdf?dl=0

Instituto Electoral de la Ciudad de México (2017). Archivo de datos. Recuperado de: https://www.dropbox. com/sh/0ptegmzw79wc9kz/AAB9h_7_oJ3R54M0 Cprd8RHa?dl=0

Instituto Electoral del Distrito Federal (s/f). Archivos de datos IECM. Recuperado de: https://www.dropbox. com/sh/0ptegmzw79wc9kz/AAB9h_7_oJ3R54M0Cpvd8RHa?dl=0

Instituto Electoral del Distrito Federal (20l4). Diseño de proyectos para el presupuesto participativo y proyectos exitosos. Ciudad de México:IEDF. Recuperado de:https://www.dropbox.com/s/wg24 I qtczsmhhxz/diseno_proyectos_elect. pdf?dl=0

Lissidini,A. (20I5). "Democracia directa en América Latina: avances, contradicciones y desafíos”, en A. Minnaert, y G. Endara (coords.), Democracia participativa e izquierdas: logros, contradicciones y desafios (pp. I2I-189). Quito: Friedrich-Ebert-Stiftung.

Montecinos, E. (2014). “Diseño institucional y participación ciudadana en los presupuestos participativos. Los casos de Chile,Argentina, Perú, República Dominicana y Uruguay". Política y gobierno, 2 I (2), 352-378.

Portillo, E. (20I2). Institucionalización del referéndum en México. México: Miguel Ángel Porrúa. 
Bibliografía
Prud'homme,J.F.(20I2). Consulta popular y democracia directa. México: Instituto Nacional Electoral.

Ramírez, E. (2006). “Programa 'Decidamos Juntos' (presupuesto participativo) en el municipio de Santa Catarina, Nuevo León, México”, en F. Mariñez (comp.), Ciudadanos, decisiones públicas y calidad de la democracia (pp. 28I-294). México: Limusa Editores, Tecnológico de Monterrey.

Ramírez García, G. (20II). "El presupuesto participativo. Experiencia del municipio de Ecatepec de Morelos", en C.A. Briseño Becerra (coord.), Presupuesto participativo. Herramienta para la democracia (pp. 107-124). México: Instituto Electoral y de Participación Ciudadana de Jalisco.

Rendón, A. (2004). "Porto Alegre, un modelo de presupuesto participativo". POLIS, I(4), 9-36.

Sandoval Díaz,J.A. (20I I)."El programa de intervención por objetivos: una experiencia de democracia participativa en la ciudad de Guadalajara", en C.A. Briseño Becerra (coord.), Presupuesto participativo. Herramienta para la democracia (pp. 175-180). México: Instituto Electoral y de Participación Ciudadana de Jalisco.

Zovatto, D. (2008). "Las instituciones de la democracia directa a nivel nacional en América Latina. Balance comparado: 1978-2007”, en A. Lissidini, Y. Welp, y D. Zovatto (coords.), Democracia directa en Latinoamérica (pp. 253-295). Buenos Aires: Prometeo. 